Artigo de Revisáo e/ou Atualização de Literatura

\title{
Intervenção não farmacológica no manejo de delirium: uma revisão bibliográfica integrativa
}

\author{
Nonpharmacological intervention in the management of delirium: an \\ integrative bibliographic review
}

Giovanna Marina Caetano ${ }^{a}$ (D), Barbara Tiemi Niyama ${ }^{a}$ (D), Maria Helena Morgani de Almeida ${ }^{a}$ (D), Marina Picazzio Perez Batista ${ }^{a}$ (D), Ana Paula Pelegrini Ratier ${ }^{a}$ (D)

${ }^{a}$ Faculdade de Medicina, Universidade de São Paulo - USP, São Paulo, SP, Brasil.

Como citar: Caetano, G. M., Niyama, B. T., Almeida, M. H. M., Batista, M. P. P., \& Ratier, A. P. P. (2021). Intervenção não farmacológica no manejo de delirium: uma revisão bibliográfica integrativa. Cadernos Brasileiros de Terapia Ocupacional, 29, e2909. https://doi.org/10.1590/2526-8910.ctoAR2198

\begin{abstract}
$\underline{\text { Resumo }}$
Introduçáo: $\mathrm{O}$ delirium é um quadro clínico complexo caracterizado por uma expressão neuropsiquiátrica de doença orgânica, em que o indivíduo apresenta súbita alteração da capacidade cognitiva, possíveis flutuaçóes do sono, consciência e atenção. $\mathrm{O}$ tratamento do delirium deve ser realizado por meio de uma abordagem multicomponente e interdisciplinar. Objetivo: Conhecer as intervençôes não farmacológicas para o manejo de delirium por equipe multiprofissional e aquelas conduzidas especificamente pelo terapeuta ocupacional. Método: Revisão bibliográfica integrativa da literatura indexada nas bases Lilacs, Pubmed, Scopus e Web of Science e SciELO sem recorte temporal. Resultados: As intervençóes visavam o empoderamento e a participaçáo de todos os agentes envolvidos no tratamento do paciente com delirium. Destacaram-se estratégias voltadas para: o aumento da autonomia e da independência do paciente; adequação das condiçóes ambientais, de modo a promover segurança, conforto, familiaridade e orientaçáo temporal-espacial; adaptação da rotina para favorecer o ciclo sono-vigília; estimulação física, cognitiva e sensorial; melhora do desempenho ocupacional e estímulo à realizaçáo de atividades significativas; prescriçáo de recursos de tecnologia assistiva e terapias complementares, quando indicado; avaliaçáo e monitoramento constante do paciente; controle da dor, de sintomas emocionais e de condiçóes clínicas que predispóem ao delirium; melhora da comunicação do paciente e sua vinculaçáo com a equipe e com a rede de apoio; e educação em saúde. Conclusáo: As intervençóes visam à integralidade do cuidado e devem, portanto, ser realizadas pelos diferentes profissionais que componham a equipe, destacando-se o papel que os terapeutas ocupacionais exercem no gerenciamento do delirium.
\end{abstract}

Palavras-chave: Delírio, Administração dos Cuidados ao Paciente, Terapia Ocupacional. 


\begin{abstract}
$\underline{\text { Abstract }}$
Introduction: Delirium is a complex clinical condition characterized by a neuropsychiatric expression organic disease, in which the individual has a sudden change in cognitive capacity, possible fluctuations in sleep, awareness, and attention. The treatment of delirium must be carried out using a multicomponent and interdisciplinary approach. Objective: Learning about non-pharmacological interventions for the management of delirium by a multidisciplinary team and those conducted specifically by the occupational therapist. Method: Integrative bibliographic review on Lilacs, Pubmed, Scopus and Web of Science database and SciELO. Results: The interventions aimed at the empowerment and participation of all agents involved in the treatment of patients with delirium. We highlight strategies focused on: increasing patient autonomy and independence; adequacy of environmental conditions, promote safety, comfort, familiarity, and temporal-spatial orientation; adaptation of the routine to favor the sleep-wake cycle; physical, cognitive, and sensory stimulation; improving occupational performance and encouraging significant activities; prescription of assistive technology resources and complementary therapies, when indicated; constant evaluation and monitoring of the patient; control of pain, emotional symptoms and clinical conditions that predispose to delirium; improved communication of the patient and his bonding with the team and the support network; and health education. Conclusion: Interventions aim at integrality of care and therefore, must be carried out by the different professionals that compose the team, highlighting the role that occupational therapists play in the management of delirium.
\end{abstract}

Keywords: Delirium, Patient Care Management, Occupational Therapy.

\title{
Introduçáo
}

O delirium é uma manifestação neuropsiquiátrica de doença orgânica, correspondente a um quadro clínico multifatorial caracterizado por um declínio agudo da capacidade cognitiva, podendo apresentar episódios de instabilidade nos níveis de atenção e consciência, além de confusóes e pensamentos desorganizados (Oh-Park et al., 2018).

A prevalência do delirium na população geral é de cerca de 1-2\%, no entanto, aumenta severamente em pessoas idosas, podendo chegar a $87 \%$ em casos de hospitalização (American Psychiatric Association, 2014). Além de a idade avançada se constituir como uma importante condição de risco, tem-se a hospitalização como principal fator precipitante do delirium, devido à grande variação ambiental e de rotina imposta (van Velthuijsen et al., 2018). Ainda, condutas adotadas no ambiente hospitalar podem aumentar o risco do desenvolvimento de quadros de delirium, por exemplo, o uso de aparelhos de ventilação mecânica, imobilização e medicamentos sedativos (Balas et al., 2014).

O delirium pode ser classificado como hiperativo, hipoativo ou misto, de acordo com o nível de atividade psicomotora apresentado pelo paciente. O subtipo hiperativo é o mais frequentemente reconhecido e o hipoativo o mais comum em idosos (American Psychiatric Association, 2014). A flutuação dos sintomas que caracterizam o delirium pode dificultar, além de seu diagnóstico, o estabelecimento de uma comunicação entre paciente e equipe, 
implicando assim a necessidade de implementar estratégias não farmacológicas (Rosen et al., 2015).

Estudos apontam o manejo não farmacológico como importante forma de prevenção de casos de delirium, por meio de medidas ambientais e de suporte. $\mathrm{O}$ uso de fármacos pode ser posteriormente adotado, se necessário, como parte de uma abordagem multicomponente (Robinson \& Eiseman, 2008; Hipp \& Ely, 2012).

Segundo Morandi et al. (2019), o tratamento do delirium deve se basear em uma abordagem interdisciplinar e multidimensional, envolvendo diferentes profissionais de saúde. Compreende-se que intervençôes de Terapia Ocupacional reduzem os impactos da patologia e permitem açóes com foco na prevenção (Tobar et al., 2017; Álvarez et al., 2017; Herling et al., 2018).

Uma busca assistemática na literatura sugeriu escassez de estudos que enfatizam as intervenções não farmacológicas para o manejo do delirium. Neste contexto, conduziu-se uma revisão bibliográfica integrativa que objetivou conhecer intervençóes não farmacológicas para o manejo de delirium por equipe multiprofissional, e verificar a atuação do terapeuta ocupacional com esta população.

\section{Metodologia}

A presente pesquisa foi desenvolvida nos moldes de uma revisão bibliográfica integrativa. Esta é o tipo mais abrangente de revisão, pois permite a inclusão de estudos experimentais, não experimentais e ainda a combinação de dados da literatura empírica e teórica (Whittemore \& Knafl, 2005). O trabalho foi conduzido conforme as seguintes fases: elaboração da pergunta norteadora; busca ou amostragem na literatura; coleta de dados; análise crítica dos estudos incluídos; discussão dos resultados; e apresentação da revisão integrativa (Souza et al., 2010).

O estudo foi desenvolvido por duas estudantes de graduação, sendo uma voluntária inscrita no Programa Institucional de Bolsas de Iniciação Científica da USP (PIBIC-USP) e uma bolsista pelo Programa Unificado de Bolsas de Estudos para Apoio à Permanência e Formação de Estudantes de Graduação (PUB-USP) da Universidade de São Paulo.

Para a seleção dos artigos deste estudo, foram definidos como critérios de inclusão: artigos originais, de revisão da literatura ou de relato de experiência; com revisão pelos pares; em português, inglês e espanhol; indexados nas bases Lilacs, Pubmed, Scopus e Web of Science e SciELO; que se relacionavam com estratégias de intervençôes não farmacológicas da terapia ocupacional ou de equipe multiprofissional voltadas à prevenção ou manejo de delirium; e artigos que reuniam população com diferentes condiçôes clínicas, desde que uma delas fosse o delirium. Visando maior abrangência na busca, não se realizou filtros por ano de publicação nas bases de dados. Foram excluídos artigos que abordavam somente estratégias farmacológicas voltadas ao delirium ou a outras condiçóes de saúde correlatas; estudos de avaliação e validação de instrumentos; editoriais, cartas, resumos expandidos e resenhas de livros.

Os descritores utilizados foram delirium e manejo, respectivamente em inglês, delirium $e$ management, combinados com o operador lógico booleano " $A N D$ ". $\mathrm{Na}$ busca. especificou-se a necessidade de que o termo estivesse presente no título do artigo. Tal estratégia teve como finalidade encontrar materiais que abordassem como tema central o manejo do delirium. Com o objetivo de garantir que se encontrassem os artigos que 
versavam sobre as intervençóes conduzidas especificamente pelo terapeuta ocupacional no delirium, e reconhecer se estas eram realizadas ou náo em conjunto com outros profissionais, buscou-se complementar os dados da primeira busca realizando uma segunda. Esta incluiu o descritor "terapia ocupacional", utilizado em inglês, "occupational therapy" combinado com "delirium" e "management" a partir do operador lógico booleano "AND". Foram reproduzidos os mesmos procedimentos da primeira busca, com exceção de que a segunda foi realizada por tópico.

Os resultados obtidos em cada base foram exportados para o gerenciador de dados Start, ferramenta de gerenciamento bibliográfico desenvolvida pelo Laboratório de Pesquisa em Engenharia de Software (LaPES), da Universidade Federal de São Carlos (UFSCar). Inicialmente, realizou-se a seleção dos estudos encontrados com a leitura dos títulos, seus respectivos resumos e palavras-chave, de modo independente e cego por dois revisores, segundo os critérios de inclusão e exclusão. Os estudos selecionados nesta primeira busca foram lidos na íntegra para definição quanto à sua inclusão ou exclusão. Um terceiro revisor foi consultado quando houve divergências na seleçáo de artigos entre os dois revisores.

Os dados dos estudos da amostra final foram extraídos e sistematizados em quadros, conforme o protocolo Start. O rigor dos estudos selecionados foi analisado segundo o nível de evidência, em conformidade com a definiçáo de Stillwell et al. (2010).

\section{Resultados}

A Figura 1 apresenta o fluxograma do processo de seleção dos artigos.

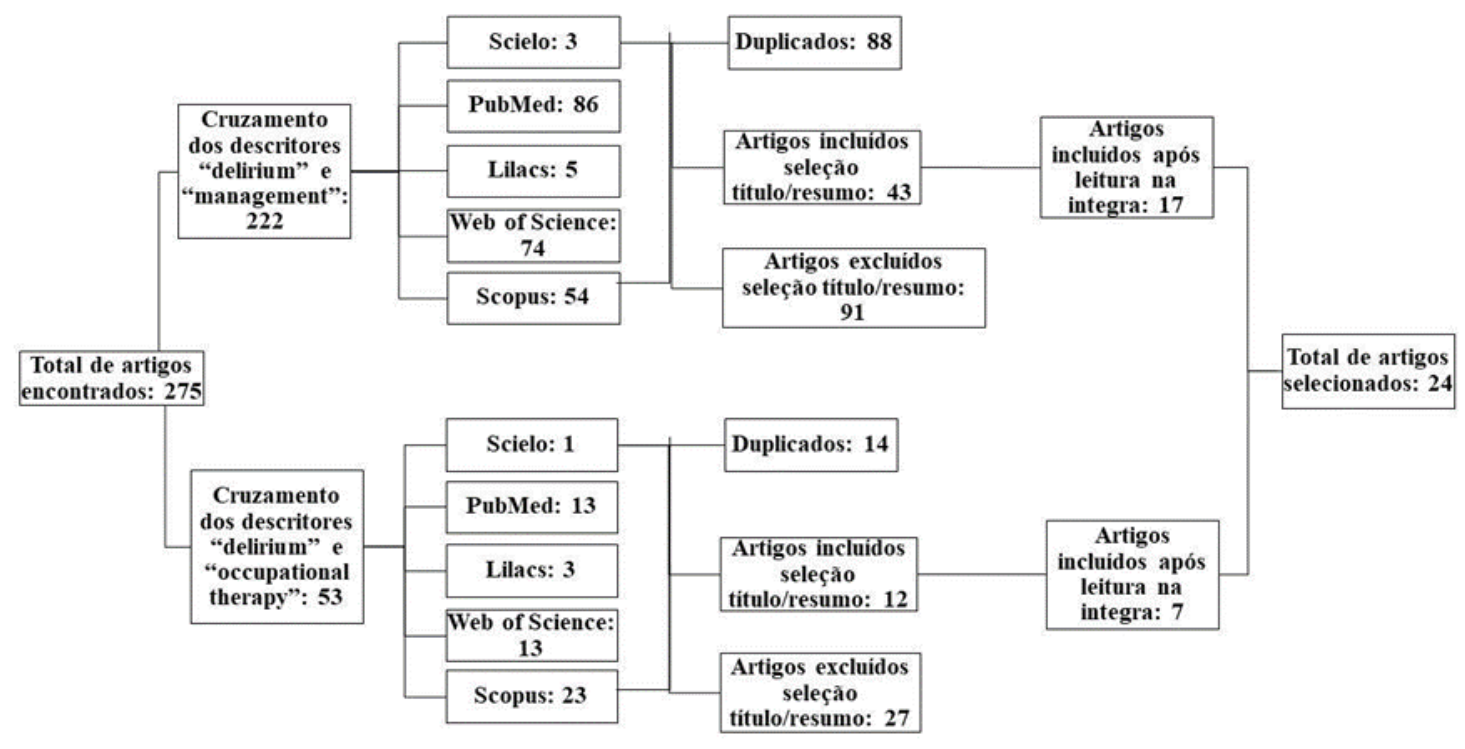

Figura 1. Fluxograma do processo de seleção dos artigos. São Paulo - SP, 2020.

Fonte: Elaborado pelas autoras, 2020.

As características gerais dos artigos selecionados foram dispostas na Tabela 1. 
Tabela 1. Características gerais dos artigos incluídos na revisão. São Paulo - SP, 2020.

\begin{tabular}{|c|c|c|c|c|c|c|c|}
\hline Autor (es) & Periódico & Ano & País & Idioma & $\begin{array}{l}\text { Delineamento } \\
\text { de estudo }\end{array}$ & $\begin{array}{l}\text { Populaçáo do } \\
\text { estudo }\end{array}$ & $\begin{array}{l}\text { Nível de } \\
\text { evidência } \\
\text { científica }\end{array}$ \\
\hline Banh (2012) & $\begin{array}{c}\text { Journal of Pharmacy } \\
\text { and Pharmaceutical } \\
\text { Sciences }\end{array}$ & 2012 & Canadá & Inglês & $\begin{array}{l}\text { Revisão de } \\
\text { literatura }\end{array}$ & $\begin{array}{c}\text { Pacientes adultos } \\
\text { com doenças } \\
\text { críticas }\end{array}$ & $\mathrm{V}$ \\
\hline $\begin{array}{l}\text { Chevrolet \& } \\
\text { Jolliet (2007) }\end{array}$ & Critical care Journal & 2007 & Suíça & Inglês & $\begin{array}{l}\text { Revisão de } \\
\text { literatura }\end{array}$ & $\begin{array}{c}\text { Pacientes } \\
\text { criticamente } \\
\text { enfermos } \\
\text { internados na } \\
\text { UTI }\end{array}$ & $\mathrm{V}$ \\
\hline $\begin{array}{c}\text { El } \\
\text { Majzoub et al. } \\
(2019)\end{array}$ & $\begin{array}{l}\text { Annals of palliative } \\
\text { medicine }\end{array}$ & 2019 & Líbano & Inglês & $\begin{array}{l}\text { Revisão de } \\
\text { literatura }\end{array}$ & $\begin{array}{l}\text { Pacientes com } \\
\text { câncer }\end{array}$ & $\mathrm{V}$ \\
\hline $\begin{array}{l}\text { Finucane et al. } \\
\qquad(2017)\end{array}$ & $\begin{array}{l}\text { Journal Psycho- } \\
\text { oncology }\end{array}$ & 2017 & Reino Unido & Inglês & $\begin{array}{l}\text { Revisão de } \\
\text { literatura }\end{array}$ & $\begin{array}{l}\text { Cuidadores de } \\
\text { pacientes } \\
\text { terminais com } \\
\text { delirium }\end{array}$ & $\mathrm{V}$ \\
\hline $\begin{array}{l}\text { Hipp \& Ely } \\
\text { (2012) }\end{array}$ & $\begin{array}{l}\text { Neurotherapeutics: } \\
\text { the journal of the } \\
\text { American Society for } \\
\text { Experimental }\end{array}$ & 2012 & Estados Unidos & Inglês & $\begin{array}{l}\text { Revisão de } \\
\text { literatura }\end{array}$ & $\begin{array}{l}\text { Pacientes com } \\
\text { doenças críticas }\end{array}$ & $\mathrm{V}$ \\
\hline $\begin{array}{l}\text { Hughes et al. } \\
\text { (2012) }\end{array}$ & $\begin{array}{c}\text { Best Practice \& } \\
\text { Research Clinical } \\
\text { Anaesthesiology }\end{array}$ & 2012 & Estados Unidos & Inglês & $\begin{array}{l}\text { Revisão de } \\
\text { literatura }\end{array}$ & Não especifica & $\mathrm{V}$ \\
\hline $\begin{array}{l}\text { Irwin et al. } \\
\text { (2013) }\end{array}$ & $\begin{array}{l}\text { Journal of palliative } \\
\text { medicine }\end{array}$ & 2013 & Estados Unidos & Inglês & $\begin{array}{l}\text { Revisão de } \\
\text { literatura }\end{array}$ & $\begin{array}{l}\text { Profissionais de } \\
\text { saúde }\end{array}$ & V \\
\hline $\begin{array}{l}\text { Kalish et al. } \\
\text { (2014) }\end{array}$ & $\begin{array}{l}\text { American Family } \\
\text { Physician }\end{array}$ & 2014 & Estados Unidos & Inglês & $\begin{array}{l}\text { Revisão de } \\
\text { Literatura }\end{array}$ & Idosos & $\mathrm{V}$ \\
\hline $\begin{array}{l}\text { Kolanowski et } \\
\text { al. (2016) }\end{array}$ & $\begin{array}{c}\text { Journal of the } \\
\text { American Geriatrics } \\
\text { Society }\end{array}$ & 2016 & Estados Unidos & Inglês & $\begin{array}{l}\text { Estudo } \\
\text { randomizado } \\
\text { controlado }\end{array}$ & $\begin{array}{c}\text { Idosos } \\
\text { hospitalizados que } \\
\text { apresentavam } \\
\text { estágio leve a } \\
\text { moderado de } \\
\text { demência e } \\
\text { delirium }\end{array}$ & II \\
\hline $\begin{array}{l}\text { Meagher } \\
\text { (2001) }\end{array}$ & $\begin{array}{l}\text { British Medical } \\
\text { Journal }\end{array}$ & 2001 & Reino Unido & Inglês & $\begin{array}{l}\text { Revisão de } \\
\text { literatura }\end{array}$ & Não especifica & $\mathrm{V}$ \\
\hline $\begin{array}{l}\text { Morandi et al. } \\
\quad(2017)\end{array}$ & $\begin{array}{l}\text { Critical Care } \\
\text { Medicine }\end{array}$ & 2017 & Itália & Inglês & $\begin{array}{c}\text { Artigo } \\
\text { qualitativo }\end{array}$ & Não especifica & VI \\
\hline $\begin{array}{l}\text { Oh-Park et al. } \\
\quad(2018)\end{array}$ & $\begin{array}{c}\text { American } \\
\text { JournalPhysical } \\
\text { Medicine \& } \\
\text { Rehabilitation }\end{array}$ & 2018 & Estados Unidos & Inglês & $\begin{array}{l}\text { Revisão de } \\
\text { literatura }\end{array}$ & $\begin{array}{c}\text { Pacientes } \\
\text { internados em } \\
\text { instalaçóes de } \\
\text { reabilitação }\end{array}$ & $\mathrm{V}$ \\
\hline $\begin{array}{l}\text { Quiroz et al. } \\
\text { (2014) }\end{array}$ & $\begin{array}{l}\text { Revista Chilena de } \\
\text { Neuro-Psiquiatría }\end{array}$ & 2014 & Chile & Espanhol & $\begin{array}{l}\text { Revisão de } \\
\text { literatura }\end{array}$ & Idosos & $\mathrm{V}$ \\
\hline $\begin{array}{l}\text { Robinson \& } \\
\text { Eiseman } \\
(2008)\end{array}$ & $\begin{array}{l}\text { Clinical interventions } \\
\text { in aging }\end{array}$ & 2008 & Estados Unidos & Inglês & $\begin{array}{l}\text { Revisão de } \\
\text { literatura }\end{array}$ & Idosos & $\mathrm{V}$ \\
\hline $\begin{array}{l}\text { Rosen et al. } \\
\text { (2015) }\end{array}$ & $\begin{array}{l}\text { Advanced Emergency } \\
\text { Nursing Journal }\end{array}$ & 2015 & Estados Unidos & Inglês & $\begin{array}{l}\text { Revisão de } \\
\text { literatura }\end{array}$ & $\begin{array}{c}\text { Idosos com } \\
\text { delirium } \\
\text { atendidos no } \\
\text { departamento de } \\
\text { emergência }\end{array}$ & $\mathrm{V}$ \\
\hline
\end{tabular}


Tabela 1. Continuação...

\begin{tabular}{|c|c|c|c|c|c|c|c|}
\hline Autor (es) & Periódico & Ano & País & Idioma & $\begin{array}{c}\text { Delineamento } \\
\text { de estudo }\end{array}$ & $\begin{array}{l}\text { Populaçáo do } \\
\text { estudo }\end{array}$ & $\begin{array}{l}\text { Nível de } \\
\text { evidência } \\
\text { científica }\end{array}$ \\
\hline $\begin{array}{l}\text { Salawu et al. } \\
\text { (2009) }\end{array}$ & $\begin{array}{c}\text { Annals of African } \\
\text { medicine }\end{array}$ & 2009 & Nigéria & Inglês & $\begin{array}{l}\text { Revisão de } \\
\text { literatura }\end{array}$ & Não especifica & $\mathrm{V}$ \\
\hline $\begin{array}{l}\text { van } \\
\text { Velthuijsen } \\
\text { et al. (2018) }\end{array}$ & $\begin{array}{l}\text { International Journal } \\
\text { of Geriatric Psychiatry }\end{array}$ & 2018 & Holanda & Inglês & $\begin{array}{l}\text { Estudo de } \\
\text { coorte } \\
\text { retrospectivo }\end{array}$ & $\begin{array}{l}\text { Pacientes idosos } \\
\text { diagnosticados } \\
\text { com delirium }\end{array}$ & IV \\
\hline $\begin{array}{l}\text { Álvarez et al. } \\
\text { (2012) }\end{array}$ & $\begin{array}{c}\text { Revista Chilena de } \\
\text { Terapia Ocupacional }\end{array}$ & 2012 & Chile & Espanhol & $\begin{array}{l}\text { Ensaio clínico } \\
\text { randomizado }\end{array}$ & $\begin{array}{l}\text { Pacientes idosos } \\
\text { internados em } \\
\text { unidade de terapia } \\
\text { intensiva }\end{array}$ & II \\
\hline $\begin{array}{l}\text { Cavallazzi et al. } \\
\text { (2012) }\end{array}$ & $\begin{array}{c}\text { Annals of Intensive } \\
\text { Care }\end{array}$ & 2012 & Estados Unidos & Inglês & $\begin{array}{l}\text { Revisão de } \\
\text { Literatura }\end{array}$ & $\begin{array}{c}\text { Pacientes } \\
\text { internados em } \\
\text { unidade de terapia } \\
\text { intensiva }\end{array}$ & V \\
\hline $\begin{array}{l}\text { Ibrahim et al. } \\
\text { (2018) }\end{array}$ & $\begin{array}{l}\text { Journal of the } \\
\text { American Heart } \\
\text { Association }\end{array}$ & 2018 & Estados Unidos & Inglês & $\begin{array}{l}\text { Revisão de } \\
\text { Literatura }\end{array}$ & $\begin{array}{c}\text { Pacientes da } \\
\text { unidade de } \\
\text { tratamento } \\
\text { intensivo cardíaco }\end{array}$ & V \\
\hline $\begin{array}{l}\text { Morandi et al. } \\
\text { (2019) }\end{array}$ & BMC Geriatrics & 2019 & Itália & Inglês & $\begin{array}{l}\text { Revisão de } \\
\text { Literatura }\end{array}$ & Não especifica & $\mathrm{V}$ \\
\hline $\begin{array}{l}\text { Pozzi et al. } \\
\text { (2020) }\end{array}$ & $\begin{array}{c}\text { European Geriatric } \\
\text { Medicine }\end{array}$ & 2020 & Suíça & Inglês & $\begin{array}{l}\text { Revisão de } \\
\text { Literatura }\end{array}$ & Idosos & $\mathrm{V}$ \\
\hline $\begin{array}{l}\text { Rains \& Chee } \\
\text { (2017) }\end{array}$ & $\begin{array}{l}\text { Journal of the } \\
\text { Intensive Care Society }\end{array}$ & 2017 & Reino Unido & Inglês & $\begin{array}{l}\text { Revisão de } \\
\text { Literatura }\end{array}$ & Não especifica & $\mathrm{V}$ \\
\hline $\begin{array}{l}\text { Tobar et al. } \\
\text { (2017) }\end{array}$ & $\begin{array}{l}\text { Revista Brasileira de } \\
\text { Terapia Intensiva }\end{array}$ & 2017 & Chile & Inglês & $\begin{array}{l}\text { Revisão de } \\
\text { Literatura }\end{array}$ & Não especifica & $\mathrm{V}$ \\
\hline
\end{tabular}

Conforme os dados sistematizados, os artigos abordavam o manejo do delirium em diferentes populaçóes: idosos $(n=8)$, pacientes com doenças críticas $(n=6)$, cuidadores de pacientes terminais $(n=1)$, pacientes com câncer $(n=1)$, profissionais de saúde $(n=1)$ e população náo especificada $(\mathrm{n}=7)$.

No que tange ao local de realização destes estudos, identificou-se: UTI ( $n=10)$, hospitais $(n=4)$, instalaçôes de reabilitação $(n=1)$, departamento de emergência $(n=1)$ e local não especificado $(\mathrm{n}=5)$. Ainda, 3 estudos apontaram que as estratégias para manejo do delirium poderiam ser aplicadas em mais de um local, sendo: UTI, instalaçóes de cuidados a longo-prazo, cuidados paliativos e na comunidade (Kalish et al., 2014); UTI, instalaçôes de reabilitação e lares de idosos (Pozzi et al., 2020); e em qualquer espaço de cuidado, incluindo a atenção no domicílio (Irwin et al., 2013).

Em poucos estudos foram apontadas limitaçóes, sendo que em $17 \%$ essas se referiam à coleta de dados, e em $4 \%$ correspondiam a não mensuraçáo da eficácia do protocolo de intervençáo aplicado. Em relação às sugestóes para estudos futuros, 54\% explicitaram a necessidade de mais pesquisas relacionadas ao tema, $4 \%$ indicaram que a participação do usuário e seus familiares na construção do tratamento também deve ser abordada. Acrescenta-se que $21 \%$ dos artigos náo indicaram limitaçóes ou sugestóes para novos estudos.

Uma questão abordada nos estudos se referiu ao delirium do subtipo hipoativo, o qual não é frequentemente identificado nas avaliaçóes disponíveis para o diagnóstico de delirium ou está associado a um início tardio do tratamento. Infere-se que isto ocorra, pois, frequentemente, os pacientes com esse subtipo de delirium apresentam comportamentos apáticos, letárgicos e 
passíveis de confusão em decorrência de quadros de depressão, demência ou relacionados à sedação (Oh-Park et al., 2018; Meagher, 2001; van Velthuijsen et al., 2018; Hipp \& Ely, 2012; Hughes et al., 2012). Diferentemente, os pacientes com delirium hiperativo frequentemente apresentam sintomas visíveis, como a agitação motora, sendo mais facilmente diagnosticados (Hipp \& Ely, 2012).

A Tabela 2 mostra os profissionais que compuseram as intervençóes descritas nos artigos.

Tabela 2. Profissionais que compuseram as intervençóes. Sáo Paulo - SP, 2020.

\begin{tabular}{|c|c|c|c|c|c|c|c|c|c|c|}
\hline \multirow{2}{*}{$\begin{array}{l}\underset{8}{8} \\
\frac{b}{2}\end{array}$} & \multicolumn{2}{|c|}{ 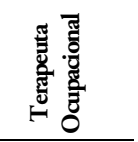 } & \multirow{2}{*}{$\frac{8}{i \frac{8}{8}}$} & \multirow{2}{*}{ 올 } & \multirow{2}{*}{ 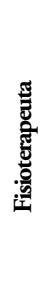 } & \multirow{2}{*}{ 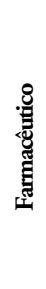 } & \multirow{2}{*}{ 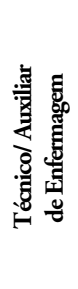 } & \multirow{2}{*}{ 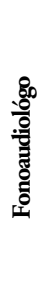 } & \multirow{2}{*}{ 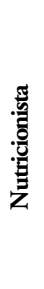 } & \multirow{2}{*}{ 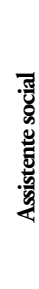 } \\
\hline & 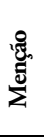 & 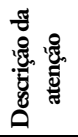 & & & & & & & & \\
\hline Álvarez et al. (2012) & $\mathrm{X}$ & $\mathrm{X}$ & $\mathrm{X}$ & $\mathrm{X}$ & & & & & & \\
\hline Banh (2012) & & & $\mathrm{X}$ & $\mathrm{X}$ & & & & & & \\
\hline Cavallazzi et al. (2012) & $\mathrm{X}$ & & & $\mathrm{X}$ & $\mathrm{X}$ & & & & & \\
\hline $\begin{array}{l}\text { Chevrolet \& Jolliet } \\
\qquad(2007)\end{array}$ & & & $\mathrm{X}$ & $\mathrm{X}$ & & & & & & \\
\hline $\begin{array}{l}\text { El Majzoub et al. } \\
\text { (2019) }\end{array}$ & & & $\mathrm{X}$ & $\mathrm{X}$ & & & & & & \\
\hline Finucane et al. (2017) & & & & $\mathrm{X}$ & & $\mathrm{X}$ & & & & \\
\hline Hipp \& Ely (2012) & & & $\mathrm{X}$ & $\mathrm{X}$ & & $\mathrm{X}$ & $\mathrm{X}$ & & & \\
\hline Hughes et al. (2012) & $\mathrm{X}$ & & $\mathrm{X}$ & $\mathrm{X}$ & $\mathrm{X}$ & & & & & \\
\hline Ibrahim et al. (2018) & $\mathrm{X}$ & & $\mathrm{X}$ & $\mathrm{X}$ & $\mathrm{X}$ & & & & & \\
\hline Irwin et al. (2013) & & & $\mathrm{X}$ & & & & & & & \\
\hline Kalish et al. (2014) & & & $\mathrm{X}$ & $\mathrm{X}$ & & & & & & \\
\hline $\begin{array}{c}\text { Kolanowski et al. } \\
\text { (2016) }\end{array}$ & & & & $\mathrm{X}$ & $\mathrm{X}$ & & & $\mathrm{X}$ & & \\
\hline Meagher (2001) & & & $\mathrm{X}$ & $\mathrm{X}$ & & & & & & \\
\hline Morandi et al. (2017) & $\mathrm{X}$ & & & & & & & & & \\
\hline Morandi et al. (2019) & $\mathrm{X}$ & $\mathrm{X}$ & $\mathrm{X}$ & $\mathrm{X}$ & $\mathrm{X}$ & $\mathrm{X}$ & $\mathrm{X}$ & $\mathrm{X}$ & $\mathrm{X}$ & $\mathrm{X}$ \\
\hline Oh-Park et al. (2018) & & & $\mathrm{X}$ & $\mathrm{X}$ & & & & & & \\
\hline Pozzi et al. (2020) & $\mathrm{X}$ & $\mathrm{X}$ & $\mathrm{X}$ & $\mathrm{X}$ & $\mathrm{X}$ & & & & & \\
\hline Quiroz et al. (2014) & $\mathrm{X}$ & $\mathrm{X}$ & & $\mathrm{X}$ & & & & & & \\
\hline Rains \& Chee (2017) & $\mathrm{X}$ & $\mathrm{X}$ & & & $\mathrm{X}$ & & & & & \\
\hline $\begin{array}{l}\text { Robinson \& Eiseman } \\
\qquad(2008)\end{array}$ & & & $\mathrm{X}$ & $\mathrm{X}$ & & & & & & \\
\hline
\end{tabular}


Tabela 2. Continuação...

\begin{tabular}{|c|c|c|c|c|c|c|c|c|c|c|}
\hline \multirow{2}{*}{$\begin{array}{l}\text { क्ष } \\
\text { 兽 }\end{array}$} & \multicolumn{2}{|c|}{ 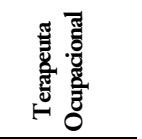 } & \multirow{2}{*}{$\frac{8}{\frac{8}{80}}$} & \multirow{2}{*}{ 题 } & \multirow{2}{*}{ 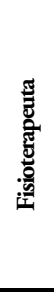 } & \multirow{2}{*}{ 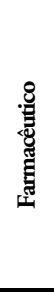 } & \multirow{2}{*}{ 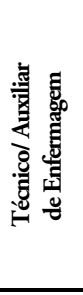 } & \multirow{2}{*}{ 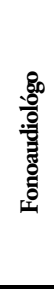 } & \multirow{2}{*}{ 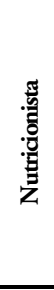 } & \multirow{2}{*}{ 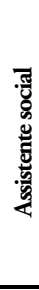 } \\
\hline & 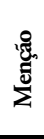 & 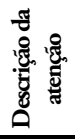 & & & & & & & & \\
\hline Rosen et al. (2015) & & & $\mathrm{X}$ & $\mathrm{X}$ & & & & & & \\
\hline Salawu et al. (2009) & & & $\mathrm{X}$ & $\mathrm{X}$ & & & & & & \\
\hline Tobar et al. (2017) & $\mathrm{X}$ & $\mathrm{X}$ & & & $\mathrm{X}$ & & & & & \\
\hline $\begin{array}{l}\text { van Velthuijsen et al. } \\
\text { (2018) }\end{array}$ & $\mathrm{X}$ & $\mathrm{X}$ & $\mathrm{X}$ & $\mathrm{X}$ & & & & & & \\
\hline
\end{tabular}

Fonte: Elaborado pelas autoras, São Paulo - SP, 2020.

Os profissionais mais citados nos estudos foram enfermeiros $(\mathrm{n}=21)$ e médicos $(\mathrm{n}=17)$, sendo que, desses, 16 artigos referem ambos. Em relação ao terapeuta ocupacional, dentre os 11 artigos que mencionaram esse profissional, apenas 7 descreveram sua atuação. Identificou-se que esses estudos abordavam a atuação da terapia ocupacional em conjunto com a fisioterapia.

A Tabela 3 mostra as intervenções não farmacológicas realizadas pela equipe multiprofissional no manejo do delirium, organizadas em categorias.

Tabela 3. Categorização das intervenções não farmacológicas de prevenção e manejo de delirium. São Paulo - SP, 2020.

\begin{tabular}{|c|c|c|}
\hline Intervençóes & Autor (es) & Descriçáo e/ou finalidade da atençáo \\
\hline \multirow{6}{*}{ Iluminação ambiental } & Pozzi et al. (2020) & Adequar a iluminação ambiental \\
\hline & $\begin{array}{l}\text { Álvarez et al. (2012), Morandi et al. (2017), } \\
\text { Quiroz et al. (2014) }\end{array}$ & Adequar a iluminação ambiental para favorecer o sono \\
\hline & Cavallazzi et al. (2012) & $\begin{array}{l}\text { Expor o paciente à luz natural durante o dia e minimizar a } \\
\text { exposição à luz artificial durante a noite }\end{array}$ \\
\hline & $\begin{array}{l}\text { El Majzoub et al. (2019), Irwin et al. (2013), } \\
\text { Morandi et al. (2019), Tobar et al. (2017) }\end{array}$ & $\begin{array}{l}\text { Minimizar o excesso de estímulos luminosos usando dispositivos } \\
\text { como máscara ocular }\end{array}$ \\
\hline & Meagher (2001) & Orientar o paciente no ambiente \\
\hline & Rosen et al. (2015), Salawu et al. (2009) & $\begin{array}{c}\text { Modificar a intensidade da iluminação para indicar a mudança } \\
\text { dia/noite }\end{array}$ \\
\hline \multirow{5}{*}{$\begin{array}{l}\text { Redução de ruído } \\
\text { ambiental }\end{array}$} & Cavallazzi et al. (2012) & Reduzir os ruídos ambientais \\
\hline & $\begin{array}{c}\text { Álvarez et al. (2012), Morandi et al. (2017), Oh- } \\
\text { Park et al. (2018), Pozzi et al. (2020), } \\
\text { Quiroz et al. (2014) }\end{array}$ & Reduzir os ruídos ambientais para favorecer o sono \\
\hline & Banh (2012) & $\begin{array}{l}\text { Incorporar um protocolo que instaure momentos de silêncio duas } \\
\text { vezes ao dia em horários específicos; interromper o uso de } \\
\text { monitores ou equipamentos desnecessários; minimizar o uso do } \\
\text { telefone e conversas em torno do paciente }\end{array}$ \\
\hline & $\begin{array}{l}\text { Banh (2012), Morandi et al. (2019), Rains \& } \\
\text { Chee (2017), Tobar et al. (2017) }\end{array}$ & $\begin{array}{l}\text { Minimizar o excesso de estímulos auditivos usando dispositivos } \\
\text { como tampóes auriculares }\end{array}$ \\
\hline & Meagher (2001) & $\begin{array}{c}\text { Controlar os níveis de ruído, tendo como base }<45 \text { decibéis } \\
\text { durante o dia e }<20 \text { decibéis durante a noite }\end{array}$ \\
\hline
\end{tabular}


Tabela 3. Continuação...

\begin{tabular}{|c|c|c|}
\hline Intervençóes & Autor (es) & Descriçáo e/ou finalidade da atençáo \\
\hline \multirow{2}{*}{$\begin{array}{l}\text { Otimizaçáo da } \\
\text { temperatura do ambiente }\end{array}$} & Cavallazzi et al. (2012), Rosen et al. (2015) & Adequar a temperatura do ambiente \\
\hline & Pozzi et al. (2020) & $\begin{array}{l}\text { Abordar causas específicas que geram estresse, como por exemplo } \\
\text { excesso de calor/frio }\end{array}$ \\
\hline \multirow{6}{*}{$\begin{array}{l}\text { Estratégias de } \\
\text { (re)orientaçấo temporal e } \\
\text { espacial }\end{array}$} & $\begin{array}{l}\text { Morandi et al. (2019), Pozzi et al. (2020), } \\
\text { Tobar et al. (2017) }\end{array}$ & Implementar estratégias de (re)orientação \\
\hline & $\begin{array}{c}\text { Álvarez et al. (2012), } \\
\text { Finucane et al. (2017), } \\
\text { Ibrahim et al. (2018), Irwin et al. (2013), } \\
\text { Kalish et al. (2014), Meagher (2001), } \\
\text { Pozzi et al. (2020), Quiroz et al. (2014), } \\
\text { Rains \& Chee (2017), Rosen et al. (2015), } \\
\text { Salawu et al. (2009), } \\
\text { van Velthuijsen et al. (2018) }\end{array}$ & $\begin{array}{c}\text { Disponibilizar no quarto dispositivos de reorientaçáo temporal, em } \\
\text { locais visíveis e com informaçóes claras, como: relógios, calendários, } \\
\text { materiais de orientaçáo, lembretes e quadros com a programaçáo } \\
\text { do dia, notícias diárias veiculadas na mídia, diário pessoal do } \\
\text { paciente, falar sobre eventos familiares próximos, folhetos } \\
\text { informativos e rádio }\end{array}$ \\
\hline & $\begin{array}{l}\text { Álvarez et al. (2012), Oh-Park et al. (2018), } \\
\text { Robinson \& Eiseman (2008) }\end{array}$ & Orientar o paciente espacialmente \\
\hline & El Majzoub et al. (2019), Ibrahim et al. (2018) & Orientar o paciente com uso de lembretes diários \\
\hline & $\begin{array}{l}\text { Álvarez et al. (2012), Ibrahim et al. (2018), } \\
\text { Rosen et al. (2015) }\end{array}$ & $\begin{array}{l}\text { Fornecer frequentemente informaçóes que orientem o paciente } \\
\text { acerca do motivo de sua hospitalizaçáo }\end{array}$ \\
\hline & $\begin{array}{l}\text { Irwin et al. (2013), Meagher (2001), Oh- } \\
\text { Park et al. (2018), Rosen et al. (2015) }\end{array}$ & $\begin{array}{l}\text { Estimular a participação da família e amigos visando à reorientação } \\
\text { do paciente }\end{array}$ \\
\hline \multirow[t]{2}{*}{ Organizaçăo do ambiente } & $\begin{array}{l}\text { Finucane et al. (2017), Meagher (2001), } \\
\text { Pozzi et al. (2020) }\end{array}$ & Favorecer que o ambiente tenha objetos familiares e personalizados \\
\hline & Meagher (2001), Salawu et al. (2009) & Priorizar que o paciente fique em quartos individuais \\
\hline \multirow{7}{*}{$\begin{array}{l}\text { Estabelecimento de } \\
\text { relaçăo do paciente com a } \\
\text { equipe de funcionários }\end{array}$} & $\begin{array}{l}\text { Irwin et al. (2013), Meagher (2001), Rosen et al. } \\
\text { (2015) }\end{array}$ & $\begin{array}{l}\text { Disponibilizar, em local visível, quadros com os nomes dos } \\
\text { funcionários que o paciente tem contato }\end{array}$ \\
\hline & Kalish et al. (2014), Meagher (2001) & Minimizar mudanças na equipe de enfermagem \\
\hline & Meagher (2001) & Estabelecer profissional de referência para atendimento ao paciente \\
\hline & Irwin et al. (2013) & $\begin{array}{l}\text { Remover ou monitorar o acesso a itens perigosos, forrar as grades } \\
\text { do leito, abaixar o nível das camas o máximo possível e colocar } \\
\text { tapetes emborrachados no cháo }\end{array}$ \\
\hline & Meagher (2001) & $\begin{array}{l}\text { Permitir espaço adequado entre as camas, retirando objetos } \\
\text { desnecessários }\end{array}$ \\
\hline & Quiroz et al. (2014) & $\begin{array}{l}\text { Adicionar uma porta de acesso por cartão e ter camas hospitalares } \\
\text { baixas }\end{array}$ \\
\hline & Rosen et al. (2015) & $\begin{array}{l}\text { Posicionar o leito do paciente no campo de visão da equipe; } \\
\text { minimizar o uso de dispositivos que possam reduzir a mobilidade } \\
\text { do paciente }\end{array}$ \\
\hline
\end{tabular}

Irwin et al. (2013), Oh-Park et al. (2018),

Pozzi et al. (2020), Quiroz, Araya \& Fuentes

Garantia da segurança do paciente

(2014), Robinson \& Eiseman (2008), Rosen et al. (2015)

Salawu et al. (2009)

El Majzoub et al. (2019), Hughes et al. (2012), Ibrahim et al. (2018), Robinson \& Eiseman (2008)

Robinson \& Eiseman (2008)

Álvarez et al. (2012), Chevrolet \& Jolliet

(2007), El Majzoub et al. (2019),

Irwin et al. (2013), Oh-Park et al. (2018),

Robinson \& Eiseman (2008), Rosen et al.

(2015), Salawu et al. (2009), van

Velthuijsen et al. (2018)
Adequar o banheiro com a instalação de sensor de luz; ter leitos com proteçáo alta nas cabeceiras

Avaliar a segurança do paciente e evitar o uso de equipamentos que ele possa ferir a si próprio ou aos outros

Retirar ou fixar dispositivos potencialmente prejudiciais, como: linhas, cateteres, foleys, tubos nasogástricos ou conectores de acesso intravenoso

Monitorar pacientes que apresentam risco de automutilação

Reduzir o uso de restriçóes físicas ou considerar seu uso somente em caso de pacientes muito agitados que representem risco para si próprios ou quando outros meios de tratamento do delirium não tenham sido suficiente. 
Tabela 3. Continuação...

\begin{tabular}{|c|c|c|}
\hline Intervençóes & Autor (es) & Descriçáo e/ou finalidade da atençáo \\
\hline \multirow{2}{*}{$\begin{array}{l}\text { Correção de deficit } \\
\text { sensoriais relacionados à } \\
\text { visão ou audiçáo }\end{array}$} & $\begin{array}{l}\text { Álvarez et al. (2012), Banh (2012), } \\
\text { El Majzoub et al. (2019), Ibrahim et al. (2018), } \\
\text { Irwin et al. (2013), Kalish et al. (2014), } \\
\text { Meagher (2001), Morandi et al. (2019), } \\
\text { Oh-Park et al. (2018), Robinson \& Eiseman } \\
\text { (2008), Rosen et al. (2015) }\end{array}$ & $\begin{array}{l}\text { Disponibilizar aparelhos visuais individualizados, como: óculos, } \\
\text { lentes de contato, lupas e lentes de aumento }\end{array}$ \\
\hline & $\begin{array}{l}\text { Álvarez et al. (2012), Banh (2012), El } \\
\text { Majzoub et al. (2019), Ibrahim et al. (2018), } \\
\text { Irwin et al. (2013), Kalish et al. (2014), Meagher } \\
\text { (2001), Morandi et al. (2019), Oh-Park et al. } \\
\text { (2018), Robinson \& Eiseman (2008), } \\
\text { Rosen et al. (2015) }\end{array}$ & $\begin{array}{l}\text { Disponibilizar aparelhos auditivos individualizados, como } \\
\text { dispositivos de amplificação }\end{array}$ \\
\hline \multirow{2}{*}{ Promoção da saúde bucal } & Meagher (2001) & Disponibilizar dentaduras \\
\hline & Oh-Park et al. (2018) & Favorecer a higiene bucal \\
\hline \multirow{3}{*}{ Controle da dor } & $\begin{array}{l}\text { Ibrahim et al. (2018), Oh-Park et al. (2018), } \\
\text { Salawu et al. (2009) }\end{array}$ & Controlar a dor \\
\hline & Rains \& Chee (2017) & $\begin{array}{l}\text { Avaliar e gerenciar a dor, com base em uma abordagem } \\
\text { multifatorial }\end{array}$ \\
\hline & Rosen et al. (2015) & $\begin{array}{l}\text { Realizar palpação na pele, ossos e articulaçōes para identificar } \\
\text { pontos dolorosos; verificar a presença de dor crônica; realizar } \\
\text { analgesia adequada; em caso de lesão aguda, fazer crioterapia, } \\
\text { elevaçáo ou imobilização, se necessário }\end{array}$ \\
\hline \multirow{14}{*}{$\begin{array}{l}\text { Prevenção de outros } \\
\text { quadros clínicos } \\
\text { associados ao processo de } \\
\text { hospitalização }\end{array}$} & $\begin{array}{l}\text { Oh-Park et al. (2018), Quiroz et al. (2014), } \\
\text { Salawu et al. (2009) }\end{array}$ & Avaliar a deglutição de forma supervisionada e assistida \\
\hline & Morandi et al. (2019) & $\begin{array}{c}\text { Gerenciar a hipóxia contando com uma equipe capacitada para sua } \\
\text { prevençáo }\end{array}$ \\
\hline & $\begin{array}{l}\text { Hughes et al. (2012), Kalish et al. (2014), } \\
\text { Morandi et al. (2019), Oh-Park et al. (2018), } \\
\text { Quiroz et al. (2014), Salawu et al. (2009), Rains } \\
\text { \& Chee (2017), Robinson \& Eiseman (2008) }\end{array}$ & Manter a hidratação adequada \\
\hline & Ibrahim et al. (2018) & Monitorar o equilíbrio dos eletrólitos do paciente \\
\hline & Irwin et al. (2013) & $\begin{array}{l}\text { Monitorar a ingestáo de líquidos e reidratar o paciente com bebidas } \\
\text { que contenham sal, como sopas e bebidas esportivas }\end{array}$ \\
\hline & Robinson \& Eiseman (2008) & Prevenir a hipovolemia \\
\hline & Rosen et al. (2015) & $\begin{array}{c}\text { Monitorar os biomarcadores renais (nitrogênio uréico sanguíneo e } \\
\text { creatinina) e, caso necessário, administrar líquido intravenoso } \\
\text { isotônico }\end{array}$ \\
\hline & $\begin{array}{l}\text { Banh (2012), Morandi et al. (2019), } \\
\text { Quiroz et al. (2014), Rains \& Chee (2017), } \\
\text { Robinson \& Eiseman (2008), Oh-Park et al. } \\
\text { (2018) }\end{array}$ & Manter uma nutriçáo adequada \\
\hline & Rosen et al. (2015) & $\begin{array}{l}\text { Verificar a bexiga com ultrassom e, se necessário, esvaziá-la com um } \\
\text { cateter urinário reto }\end{array}$ \\
\hline & $\begin{array}{l}\text { Pozzi et al. (2020), Oh-Park et al. (2018), } \\
\text { Robinson \& Eiseman (2008) }\end{array}$ & Evitar a incontinência e retenção urinária \\
\hline & Oh-Park et al. (2018), Morandi et al. (2019) & Prevenir a constipação \\
\hline & Rosen et al. (2015) & $\begin{array}{l}\text { Verificar a higiene das roupas íntimas do paciente; fazer } \\
\text { exame retal se necessário; considerar a necessidade de } \\
\text { desimpactaçáo; restringir o uso de medicamentos que } \\
\text { causam constipação }\end{array}$ \\
\hline & Finucane et al. (2017), Salawu et al. (2009) & Prevenir privaçóes sensoriais \\
\hline & Oh-Park et al. (2018), Salawu et al. (2009) & Tratar as condiçóes sistêmicas subjacentes \\
\hline $\begin{array}{l}\text { Posicionamento } \\
\text { adequado no leito }\end{array}$ & $\begin{array}{l}\text { Chevrolet \& Jolliet (2007), Oh-Park et al. } \\
\qquad \text { (2018) }\end{array}$ & $\begin{array}{l}\text { Posicionar o paciente adequadamente no leito, evitando: úlceras } \\
\text { por pressão ou sensaçăo de dor na bexiga }\end{array}$ \\
\hline
\end{tabular}


Tabela 3. Continuação...

\begin{tabular}{|c|c|c|}
\hline Intervençóes & Autor (es) & Descriçáo e/ou finalidade da atençáo \\
\hline \multirow{3}{*}{$\begin{array}{l}\text { Mobilidade e exercício } \\
\text { precoces }\end{array}$} & $\begin{array}{l}\text { Álvarez et al. (2012), El Majzoub et al. (2019), } \\
\text { Hipp \& Ely (2012), Hughes et al. (2012), } \\
\text { Kalish et al. (2014), Meagher (2001), } \\
\text { Morandi et al. (2017), Morandi et al. (2019), } \\
\text { Oh-Park et al. (2018), Pozzi et al. (2020), } \\
\text { Robinson \& Eiseman (2008), } \\
\text { Tobar et al. (2017) }\end{array}$ & $\begin{array}{l}\text { Aplicar exercícios de mobilização precoce adaptados às capacidades } \\
\text { de cada paciente, favorecendo a deambulação diária, amplitude de } \\
\text { movimento e prevençáo de complicaçóes relacionadas à } \\
\text { imobilizaçáo }\end{array}$ \\
\hline & Morandi et al. (2017) & $\begin{array}{l}\text { Aplicar exercícios com amplitude de movimento passivo } \\
\text { combinado (PROM), fisioterapia ativa, deambulaçáo, } \\
\text { cicloergometria e estimulação elétrica neuromuscular }\end{array}$ \\
\hline & Rains \& Chee (2017) & $\begin{array}{l}\text { Mobilizar o paciente sentado, utilizar uma cadeira stryker para } \\
\text { transferências e motomed para a realizaçáo de exercícios passivos e } \\
\text { ativos assim que o paciente se mostrar estável }\end{array}$ \\
\hline Tecnologia Assistiva & Quiroz et al. (2014) & $\begin{array}{l}\text { Utilizar dispositivos de auxílio à marcha, como andador e bengala, } \\
\text { para auxiliar na realizaçáo de mobilizaçóes precoces }\end{array}$ \\
\hline
\end{tabular}

Hipp \& Ely (2012), Hughes et al. (2012),

Kalish et al. (2014), Morandi et al. (2019), Rains

$\&$ Chee (2017), Robinson \& Eiseman (2008),

Favorecer um sono tranquilo e ininterrupto

Tobar et al. (2017)

Álvarez et al. (2012), Ibrahim et al. (2018), Evitar a administração de medicamentos de madrugada, fechar

Meagher (2001), Morandi et al. (2017) portas e manter as luzes apagadas neste período

Estratégias de promoçáo Cavallazzi et al. (2012), Pozzi et al. (2020), Rains Facilitar o sono por meio do uso de dispositivos, como: tampóes de do sono

\& Chee (2017) ouvido e máscaras oculares

Banh (2012), Quiroz et al. (2014) Favorecer um ambiente noturno agradável por meio de: massagens, músicas relaxantes e ingestáo de bebidas mornas ou quentes

Envolver a família para passar a noite com o paciente, trazendo

van Velthuijsen et al. (2018)

travesseiros e lençóis de sua casa para tornar o ambiente hospitalar mais confortável

\section{Cavallazzi et al. (2012), Oh-Park et al. (2018), Rains \& Chee (2017) \\ Reduçáo do uso de estratégias farmacológicas \\ Álvarez et al. (2012), Kalish et al. (2014), \\ Morandi et al. (2019), Rains \& Chee (2017), \\ Oh-Park et al. (2018), Tobar et al. (2017)}

\begin{tabular}{lc}
\hline Participação do paciente & Irwin et al. (2013) \\
\cline { 2 - 2 } & Meagher (2001)
\end{tabular}

Álvarez et al. (2012), Finucane et al. (2017),

Kalish et al. (2014), Meagher (2001),

Participação e empoderamento da família

Morandi et al. (2017), Morandi et al. (2019)

Irwin et al. (2013), Meagher (2001), Rosen et al. (2015)

Chevrolet \& Jolliet (2007);

El Majzoub et al. (2019), Finucane et al.

(2017), Irwin et al. (2013), Kalish et al.

(2014), Morandi et al. (2017),

Oh-Park et al. (2018), Tobar et al. (2017)

Educação em saúde
Reduzir as sedaçōes diárias, adequando às necessidades singulares

Reduzir o uso de drogas que podem desencadear delirium. Para tanto, levar em consideração a interação com outros medicamentos, como: psicoativos, anticolinérgicos e benzodiazepínicos

Envolver o paciente no momento de preenchimento de sua documentação hospitalar

Incentivar que o paciente dê feedbacks sobre sua dor, visando promover o autocuidado e a participação no tratamento

Envolver e empoderar as famílias, incentivar sua presença e visitas prolongadas; ter uma equipe de apoio aos familiares

Estimular que os membros da família e amigos auxiliem o paciente a se comunicar e possam acalmar, ajudar, proteger, apoiar e advogar pelo paciente

Oferecer educação em saúde aos familiares e cuidadores, de forma verbal ou escrita sobre: prevenção, identificação e tratamento do delirium. Para tanto, fazer uso de orientaçōes em folhetos e livretos; e fornecer explicaçóes claras, completas e objetivas sobre as opçôes de tratamento, como lidar com o paciente com delirium e como the fornecer apoio emocional

erecer educaçáo em saúde aos profissionais sobre as causas de delirium em idosos, seus tipos, fatores de risco, sintomas prodrômicos; além das funçōes de cada membro da equipe na prevençáo desta condiçáo

Meagher (2001), Tobar et al. (2017)

Salawu et al. (2009), van Velthuijsen et al. (2018)

Especializar a equipe a respeito dos tratamentos e intervençóes específicas no delirium 
Tabela 3. Continuação...

\begin{tabular}{|c|c|c|}
\hline Intervençóes & Autor (es) & Descriçáo e/ou finalidade da atençáo \\
\hline $\begin{array}{l}\text { Intervençóes } \\
\text { psicoeducacionais para } \\
\text { reduçáo da ansiedade }\end{array}$ & Salawu et al. (2009) & $\begin{array}{c}\text { Aplicar intervençóes psicoeducacionais para diminuir ansiedade e } \\
\text { ressignificar experiências de delirium }\end{array}$ \\
\hline \multirow{3}{*}{$\begin{array}{l}\text { Comunicação entre } \\
\text { equipe e paciente }\end{array}$} & $\begin{array}{l}\text { Irwin et al. (2013), Cavallazzi et al. (2012), } \\
\text { Rosen et al. (2015) }\end{array}$ & $\begin{array}{l}\text { Melhorar a comunicação entre equipe e paciente ao: identificar-se } \\
\text { cada vez que encontrar o paciente, oferecer repetidamente } \\
\text { lembretes verbais, não utilizar linguajar extremamente técnico, } \\
\text { dirigir-se ao paciente pessoalmente com instruçóes objetivas }\end{array}$ \\
\hline & Oh-Park et al. (2018), Pozzi et al. (2020) & $\begin{array}{c}\text { Evitar confrontos com o paciente, agir de maneira calma e repetir } \\
\text { orientaçôes sempre que necessário }\end{array}$ \\
\hline & Meagher (2001) & $\begin{array}{c}\text { Considerar se é necessário um intérprete no caso de deficiências } \\
\text { sensoriais }\end{array}$ \\
\hline \multirow{3}{*}{$\begin{array}{l}\text { Avaliação e } \\
\text { monitoramento do } \\
\text { paciente pela equipe }\end{array}$} & $\begin{array}{l}\text { Hipp \& Ely (2012), Oh-Park et al. (2018), } \\
\text { Salawu et al. (2009) }\end{array}$ & $\begin{array}{l}\text { Monitorar diariamente o paciente, desde a admissão até a alta, com } \\
\text { atenção a aspectos, como: avaliar sinais vitais, status do fluido- } \\
\text { eletrólito, saturaçáo de oxigênio, status respiratório e cardiovascular, } \\
\text { possíveis infecçôes na pele, deficit neurológico }\end{array}$ \\
\hline & van Velthuijsen et al. (2018) & $\begin{array}{l}\text { Aplicar o Delirium Observation Screening, de manhã, tarde e noite, } \\
\text { para avaliar e monitorar o delirium }\end{array}$ \\
\hline & Salawu et al. (2009) & Realizar avaliação cognitiva \\
\hline Estimulação cognitiva & $\begin{array}{l}\text { Banh (2012), Hughes et al. (2012), } \\
\text { Kolanowski et al. (2016), Irwin et al. (2013), } \\
\text { Rains \& Chee (2017), Tobar et al. (2017) }\end{array}$ & $\begin{array}{l}\text { Oferecer atividades cognitivamente estimulantes, de maneira } \\
\text { precoce, regular e individualizadas }\end{array}$ \\
\hline Organização da rotina & Rains \& Chee (2017) & $\begin{array}{l}\text { Implementar uma rotina de atividades diurnas, organizada em } \\
\text { horários, incluindo tarefas funcionais e períodos de descanso }\end{array}$ \\
\hline Musicoterapia & Banh (2012), Tobar et al. (2017) & Utilizar musicoterapia \\
\hline Cromoterapia & $\begin{array}{l}\text { Quiroz et al. (2014), Salawu et al. (2009), } \\
\text { Tobar et al. (2017) }\end{array}$ & Utilizar terapia com luz \\
\hline Terapias relaxantes & Banh (2012), Quiroz et al. (2014) & $\begin{array}{l}\text { Aplicar técnicas de relaxamento e massoterapia para auxiliar na } \\
\text { melhora da agitaçáo e do sono }\end{array}$ \\
\hline $\begin{array}{l}\text { Medicina alternativa e } \\
\text { complementar }\end{array}$ & Banh (2012) & $\begin{array}{l}\text { Utilizar práticas, como: técnicas da medicina chinesa, ayurveda, } \\
\text { homeopatia/medicina naturopática, terapia assistida por animais, } \\
\text { arteterapia, imagens guiadas, meditaçáo, musicoterapia, oraçáo, } \\
\text { acupressáo, quiropraxia/terapia manipulativa e massagem, uso de } \\
\text { suplementos alimentares e produtos à base de plantas, Qigong, } \\
\text { reiki, toque terapêutico e terapias baseadas em bioeletromagnética }\end{array}$ \\
\hline Pacote ABCDEF & $\begin{array}{c}\text { Hipp \& Ely (2012), Ibrahim et al. (2018), } \\
\text { Morandi et al. (2017), Rains \& Chee (2017), } \\
\text { Tobar et al. (2017) }\end{array}$ & $\begin{array}{l}\text { Implementar as estratégias que compóem o pacote } \mathrm{ABCDEF} \text {, que } \\
\text { se referem, respectivamente, ao "teste de acordar/despertar } \\
\text { espontaneamente", "ensaios diários de respiraçáo espontânea”, à } \\
\text { escolha adequada de sedativos, à retirada do paciente da ventilação } \\
\text { mecânica e da UTI o mais breve possível, à realização de } \\
\text { mobilizaçáo precoce para reduzir o delirium e melhorar os } \\
\text { resultados cognitivos a longo prazo e realizar intervençôes que } \\
\text { visem envolver e empoderar a família }\end{array}$ \\
\hline $\begin{array}{l}\text { Programa de Vida para } \\
\text { Idosos no Hospital } \\
\text { (HELP) }\end{array}$ & $\begin{array}{l}\text { Hipp \& Ely (2012), Kalish et al. (2014), Oh- } \\
\text { Park et al. (2018), Quiroz et al. (2014) }\end{array}$ & $\begin{array}{c}\text { Reorientar o paciente com calendários de parede, quadros com } \\
\text { fotografias da família, visitas de amigos e familiares; promover a } \\
\text { mobilizaçáo precoce; favorecer um ambiente noturno tranquilo } \\
\text { com a ingestão de bebidas quentes e música agradável; reduzir a luz } \\
\text { e ruído ambiental; evitar controles desnecessários; e manter a } \\
\text { hidrataçáo e nutrição adequadas }\end{array}$ \\
\hline
\end{tabular}

Como observado na Tabela 3, o manejo do delirium é realizado por meio de diferentes intervençôes, as quais são direcionadas ao paciente, à sua rede de apoio, à vinculação destes com a equipe e ao ambiente. Além disso, foram identificadas estratégias consideradas complementares e programas estruturados multicomponentes. 


\section{Terapia ocupacional}

As intervençôes realizadas pelo terapeuta ocupacional, descritas nos artigos, de modo uniprofissional ou em conjunto com outros membros da equipe, foram organizadas e dispostas na Tabela 4.

Tabela 4. Categorização das intervençôes não farmacológicas de prevençâo e manejo de delirium realizadas por terapeutas ocupacionais. São Paulo - SP, 2020.

\begin{tabular}{|c|c|c|}
\hline Açáo da terapia ocupacional & Autor(es) & Finalidade/ Detalhamento da açáo da terapia ocupacional \\
\hline \multirow{3}{*}{$\begin{array}{l}\text { Intervenção terapêutica } \\
\text { ocupacional }\end{array}$} & Hughes et al. (2012) & Melhorar a capacidade funcional e cognitiva \\
\hline & Cavallazzi et al. (2012) & Diminuir a duração do delirium e melhorar o estado funcional \\
\hline & $\begin{array}{l}\text { Hughes et al. (2012), } \\
\text { Ibrahim et al. (2018), } \\
\text { Kolanowski et al. (2016) }\end{array}$ & Diminuir o delirium \\
\hline Modificação das atividades & Morandi et al. (2019) & $\begin{array}{l}\text { Modificar as atividades conforme habilidades funcionais e cognitivas } \\
\text { visando maior autonomia, senso de eficácia, satisfação e bem-estar }\end{array}$ \\
\hline \multirow[t]{2}{*}{ Interação social } & van Velthuijsen et al. (2018) & $\begin{array}{l}\text { Utilizar atividades com música ou arte em sala confortável para favorecer } \\
\text { interaçáo entre idosos com delirium }\end{array}$ \\
\hline & Álvarez et al. (2012) & Favorecer a interação do paciente com objetos e pessoas próximas \\
\hline $\begin{array}{l}\text { Restauração de uma } \\
\text { rotina diária }\end{array}$ & $\begin{array}{l}\text { Morandi et al. (2019), van } \\
\text { Velthuijsen et al. (2018) }\end{array}$ & $\begin{array}{c}\text { Criar uma rotina significativa, alternando atividades e períodos de } \\
\text { descanso; evitar a privaçáo ocupacional, promovendo autonomia e } \\
\text { envolvimento nas atividades cotidianas }\end{array}$ \\
\hline \multirow{4}{*}{ Estimulação Sensorial } & $\begin{array}{l}\text { Álvarez et al. (2012), } \\
\text { Tobar et al. (2017) }\end{array}$ & $\begin{array}{l}\text { Estimular os diferentes canais sensoriais do paciente (visual, auditivo, } \\
\text { tátil, proprioceptivo e gustativo), por um período de cinco dias, com } \\
\text { frequência de duas intervençóes diárias, cada uma com duraçáo de } \\
\qquad 40 \text { minutos }\end{array}$ \\
\hline & $\begin{array}{l}\text { Álvarez et al. (2012), } \\
\text { Morandi et al. (2019), } \\
\text { Pozzi et al. (2020), Tobar et al. } \\
\text { (2017) }\end{array}$ & Realizar estimulação frequente dos diferentes canais sensoriais \\
\hline & Pozzi et al. (2020) & $\begin{array}{l}\text { Fornecer estimulação multissensorial; intervir na deficiência sensorial por } \\
\text { meio de ocupaçóes significativas e familiares }\end{array}$ \\
\hline & Morandi et al. (2019) & $\begin{array}{l}\text { Reduzir estímulos sensoriais do ambiente que exacerbam o delirium no } \\
\text { paciente }\end{array}$ \\
\hline \multirow[t]{2}{*}{ Posicionamento } & $\begin{array}{l}\text { Álvarez et al. (2012), } \\
\text { Pozzi et al. (2020), Tobar et al. } \\
\text { (2017) }\end{array}$ & $\begin{array}{c}\text { Posicionar o paciente adequadamente para fornecer conforto, manter ou } \\
\text { melhorar a funcionalidade e evitar complicaçóes decorrentes da pouca } \\
\text { mobilizaçáo }\end{array}$ \\
\hline & Morandi et al. (2019) & Realizar mudanças posturais e estimular a interação com o ambiente \\
\hline Estimulação cognitiva & $\begin{array}{l}\text { Álvarez et al. (2012), Rains \& } \\
\text { Chee (2017), Pozzi et al. } \\
\text { (2020), Quiroz et al. (2014), } \\
\text { Tobar et al. (2017) }\end{array}$ & $\begin{array}{c}\text { Promover estimulação das diferentes funçóes cognitivas por meio do uso } \\
\text { da comunicação e do desempenho de atividades }\end{array}$ \\
\hline $\begin{array}{l}\text { Treinamento de atividades } \\
\text { básicas da vida diária } \\
\text { (ABVDs) }\end{array}$ & $\begin{array}{l}\text { Álvarez et al. (2012), } \\
\text { Morandi et al. (2019), } \\
\text { Pozzi et al. (2020), Tobar et al. } \\
\text { (2017) }\end{array}$ & $\begin{array}{l}\text { Diversificar a rotina; oferecer treinamento para o desempenho de } \\
\text { atividades básicas da vida diária e de lazer visando independência }\end{array}$ \\
\hline $\begin{array}{l}\text { Estimulação motora dos } \\
\text { membros superiores }\end{array}$ & $\begin{array}{l}\text { Álvarez et al. (2012), } \\
\text { Tobar et al. (2017) }\end{array}$ & $\begin{array}{l}\text { Manter ou ativar movimentos funcionais e melhorar a força dos } \\
\text { membros superiores por meio de atividades, como: exercícios com } \\
\text { equipamentos, ergoterapia e atividades bimanuais }\end{array}$ \\
\hline Tecnologia Assistiva & $\begin{array}{l}\text { Álvarez et al. (2012), } \\
\text { Morandi et al. (2019), } \\
\text { Tobar et al. (2017) }\end{array}$ & $\begin{array}{c}\text { Usar dispositivos de tecnologia assistiva para posicionamento adequado } \\
\text { e prevenção de úlceras por pressáo e deformidades }\end{array}$ \\
\hline
\end{tabular}


Tabela 4. Continuação...

\begin{tabular}{|c|c|c|}
\hline Açáo da terapia ocupacional & Autor(es) & Finalidade/ Detalhamento da açáo da terapia ocupacional \\
\hline \multirow[t]{2}{*}{ Educação em saúde } & $\begin{array}{l}\text { Morandi et al. (2019), } \\
\text { Pozzi et al. (2020), Tobar et al. } \\
\text { (2017) }\end{array}$ & $\begin{array}{l}\text { Sugerir estratégias de solução de problemas; apoiar e orientar os } \\
\text { cuidadores informais sobre o reconhecimento dos sinais e sintomas do } \\
\text { delirium, como prestar assistência adequada para realizar atividades de } \\
\text { vida diária e como comunicar-se mais adequadamente com o paciente }\end{array}$ \\
\hline & $\begin{array}{l}\text { Pozzi et al. (2020), Rains \& } \\
\text { Chee (2017) }\end{array}$ & $\begin{array}{c}\text { Oferecer educaçáo em saúde para o paciente, equipe, familiares e } \\
\text { cuidadores }\end{array}$ \\
\hline $\begin{array}{l}\text { Participaçáo dos familiares e } \\
\text { cuidadores no tratamento }\end{array}$ & $\begin{array}{l}\text { Álvarez et al. (2012), } \\
\text { Morandi et al. (2019), } \\
\text { Pozzi et al. (2020), Tobar et al. } \\
\text { (2017) }\end{array}$ & $\begin{array}{l}\text { Favorecer a presença e envolvimento da família no cuidado por meio de } \\
\text { estratégias, como: colaboração para estimulação cognitiva, participaçáo } \\
\text { em reuniōes familiares, disponibilização de materiais de orientação }\end{array}$ \\
\hline $\begin{array}{l}\text { Estratégias para promoção } \\
\text { do sono }\end{array}$ & $\begin{array}{l}\text { Pozzi et al. (2020), Rains \& } \\
\text { Chee (2017) }\end{array}$ & Promover a higiene do sono \\
\hline $\begin{array}{l}\text { Adaptaçóes } \\
\text { comportamentais }\end{array}$ & Pozzi et al. (2020) & $\begin{array}{l}\text { Relacionar-se com o paciente de maneira calma, evitando confronto, } \\
\text { repetir as informaçóes sempre que necessário, evitar trocas de } \\
\text { profissionais que estáo em contato com o paciente; incentivar o } \\
\text { autocuidado; abordar causas específicas de estresse }\end{array}$ \\
\hline Adaptaçốes ambientais & Pozzi et al. (2020) & $\begin{array}{c}\text { Modificar o ambiente; oferecer ao paciente quarto individual; ajustar a } \\
\text { iluminação e temperatura ambientais; fornecer orientaçáo temporal, } \\
\text { espacial e acesso a objetos familiares; e evitar transferências de leito } \\
\text { desnecessárias }\end{array}$ \\
\hline
\end{tabular}

O cuidado oferecido pelos terapeutas ocupacionais se concentrou em estratégias individualizadas que enfatizavam o desempenho ocupacional, a melhora das capacidades físicas e cognitivas, o posicionamento adequado, a realização de atividades significativas, $o$ aumento da autonomia, satisfação e bem-estar, o estímulo à participação da família, a promoção da educação em saúde para favorecer a interação com o paciente, o manejo de fatores comportamentais e ambientais e os possíveis disparadores de estresse no paciente.

\section{Discussão}

Este estudo permitiu evidenciar estratégias não farmacológicas para o manejo do delirium, incluindo aquelas realizadas pelo terapeuta ocupacional. Identificamos que $80 \%$ dos estudos da amostra foram classificados como de baixa evidência científica. Observouse descrições pouco elaboradas das intervençóes não farmacológicas e falta de informações sobre quais profissionais são responsáveis por sua implementação.

Diferentes populaçôes são abordadas nos estudos encontrados, porém, nem todos os autores especificaram a amostra para além de pessoas com delirium. Entretanto, vale colocar que, em maior número, os idosos foram citados como população-alvo das intervenções. Tal fato se mostrou relevante, considerando que as singularidades dos idosos devem ser acolhidas durante a hospitalização (Hammerschmidt \& Santana, 2020).

Vale também destacar que a rotina do usuário internado é estruturada por protocolos clínicos assistenciais que influenciam as relaçóes entre pacientes, equipe e serviço. No caso de um paciente hospitalizado com delirium, tais protocolos implicam uma despersonalização e dificuldade de apropriaçáo pelo paciente de seu processo de cuidado. Além disso, a própria condição de hospitalização provoca um distanciamento do cotidiano e dos ambientes com os quais o paciente se identifica (Imanishi \& Silva, 2016). Os resultados dessa pesquisa demonstram a necessidade de se debruçar sobre as tecnologias relacionais que envolvem a 
interação com o paciente no espaço assistencial, bem como sobre modificaçóes do ambiente e de protocolos rígidos que predispóem ao delirium ou a seu agravamento.

Além disso, os resultados favorecem a reflexão sobre o subdiagnóstico relacionado aos diferentes tipos existentes de delirium, fator esse que implica diretamente o prognóstico e o tratamento prestado. Compreende-se que, nos quadros de delirium, os usuários pouco comunicativos, apáticos ou que não solicitam frequentemente a equipe no decorrer do tratamento podem receber menor atenção dos profissionais, que, por vezes, consideram-se desencorajados ou esquecem de interagir com o paciente (Alasad \& Ahmad, 2005). Alguns estudos apontam ainda que a relação com pacientes não comunicativos pode gerar sentimento de frustração em profissionais atuantes no hospital (Happ et al., 2011). Assim, é possível inferir que o pouco feedback trazido pelos pacientes com delirium hipoativo influencie na interação destes com a equipe. Tal aspecto, muito possivelmente, impacta negativamente na qualidade da assistência ofertada, o que mostra a relevância do investimento em abordagens não farmacológicas para esses pacientes.

Desse modo, conforme apontado pelos estudos encontrados, torna-se importante considerar a comunicação entre equipe e paciente como uma estratégia não-farmacológica que auxilia no manejo do delirium. Indica-se que esta deva ser efetuada de maneira clara e efetiva, envolvendo um diálogo entre o profissional de referência e os outros membros da equipe. A comunicação entre paciente e equipe é fator determinante na qualidade do cuidado, de modo que é fundamental que o profissional de saúde desenvolva habilidades para compreender os aspectos comunicacionais verbais e não verbais do paciente (Kourkouta \& Papathanasiou, 2014).

A comunicação, tanto verbal quanto não verbal, permite identificar os conteúdos explícitos e implícitos que o sujeito deseja emitir. Somado a ela, a escuta implicada também se constitui como uma ferramenta essencial na área da saúde, e influencia as relaçóes intersubjetivas entre equipe, paciente e família (Campos et al., 2019). Essas ferramentas, desse modo, favorecem a compreensáo dos desejos e sentimentos de cada indivíduo em seu processo de adoecimento.

Identificou-se também pelos resultados que o tratamento do delirium deve enfatizar o protagonismo do indivíduo e de seus cuidadores na construção do plano de cuidados. Segundo Pinheiro \& Guanaes (2011), ter uma rede social de apoio é importante para reforçar sentimentos de bem-estar e ampliar o suporte para o enfrentamento de crises. Nessa perspectiva, o envolvimento do usuário e familiares favorece sua participação ativa e apropriação sobre seu cuidado, contrapondo-se à medicalização do sofrimento (Tesser \& Dallegrave, 2020).

A complexidade envolvida na condição do paciente com delirium exige uma equipe interdisciplinar com comunicaçáo constante e açóes coordenadas. Nessa perspectiva, a equipe tem potencial para elaborar um trabalho em saúde em consonância com o princípio da integralidade e que considere os campos dos conhecimentos técnico, social e cultural (Ramos \& Ferreira, 2020).

Contudo, notou-se nos resultados desta pesquisa que as intervençôes referentes ao gerenciamento do delirium, principalmente no ambiente hospitalar, encontram-se mais centralizadas nos profissionais médicos e enfermeiros. Esses, respectivamente, são os principais atores na implementação de estratégias farmacológicas e não farmacológicas. Entretanto, apesar de em menor número, outros profissionais foram identificados nos artigos, o que mostra a necessidade de investimento no trabalho em equipe para manejo 
desta condição complexa. Também vale destacar, neste manejo, as práticas integrativas e complementares que estimulam a participação dos pacientes em seus tratamentos, por se tratar da uniáo de conhecimentos populares e especializados (Tesser \& Dallegrave, 2020).

A composição de uma abordagem multicomponente é frequentemente incentivada pelos autores que discutem o manejo do delirium. A atuação do terapeuta ocupacional colabora com a implementação de intervenções não farmacológicas, visto que enfatiza a ampliação da autonomia e independência dos usuários, o envolvimento de seus clientes em atividades significativas, o empoderamento dos usuários e seus familiares, e o gerenciamento de sentimentos que trazem sofrimento.

A abordagem do terapeuta ocupacional centrada no cliente implica estratégias adequadas a cada indivíduo. Nesta perspectiva, esta requer uma compreensão que considere as habilidades físicas e cognitivas do sujeito; seus contextos social, cultural e relacional; seu modo de existir singular; suas experiências subjetivas; seus valores e conhecimentos (World Federation of Occupational Therapists, 2010). Esta complexidade demanda a construçáo de um plano de cuidado conjunto, contrapondo-se à centralização do conhecimento na figura do profissional, e que favoreça a corresponsabilização da pessoa em seu próprio processo saúde-doença (Agreli et al., 2016).

Apesar da evidente relevância da terapia ocupacional no manejo do delirium, apenas $45 \%$ dos artigos selecionados abordavam a atuação deste profissional. Destes, $16 \%$ citaram brevemente a presença da profissão na equipe de tratamento, normalmente em conjunto com práticas fisioterapêuticas, e 29\% explicitaram quais intervençôes eram realizadas pelo terapeuta ocupacional. Portanto, ainda existem poucos estudos que reúnem as intervençóes específicas da terapia ocupacional e que apontam detalhadamente como estas são realizadas. Embora em número reduzido, esses artigos demonstram a importância desse profissional no tratamento do delirium.

Entende-se que os terapeutas ocupacionais que atuam em contextos hospitalares compreendem a relevância de seu trabalho e são engajados no que fazem. Porém, frequentemente enfrentam dificuldades na valorização de suas práticas pela equipe, com pouco reconhecimento e legitimaçáo, experimentando sentimentos de invisibilidade (Galheigo \& Tessuto, 2010).

Mas, vale reiterar que o manejo do delirium deva abordar os aspectos biopsicossociais do indivíduo com base em uma equipe interdisciplinar, baseada na integralidade e humanização do cuidado. Segundo Pozzi et al. (2020), estudos recentes mostraram a eficácia da implementação de programas multicomponentes e multidisciplinares de reabilitação, com ênfase na melhora das funçóes cognitivas de pacientes hospitalizados com delirium. Essas intervençóes devem ser realizadas de forma individualizada e com o maior envolvimento do terapeuta ocupacional que, de acordo com evidências, resulta em menores índices de reinternação hospitalar (Pozzi et al., 2020).

Por fim, notou-se que a não especificação de quais profissionais realizam determinadas intervençôes citadas nos estudos, por vezes, permite a interpretação de que podem ser executadas por quaisquer profissionais, acarretando desvalorização das profissóes. Reconhece-se que é o terapeuta ocupacional o profissional cujo foco de ação reside na relação intrínseca entre o indivíduo, seu contexto ambiental, social e cultural, e o desempenho de atividades cotidianas significativas ao sujeito (Pozzi et al., 2020; Tobar et al., 2017). Pode-se tomar como exemplo que os artigos colocam a relevância da disponibilização de dispositivos de orientação temporal e espacial no ambiente e de objetos 
de familiaridade do sujeito, mas náo apontam para a necessidade de considerar a singularidade da pessoa nesta prescrição e o quanto estas estratégias podem interferir na relaçáo da pessoa com o ambiente e com sua rede relacional.

Historicamente, a terapia ocupacional tem buscado assegurar seu papel nas equipes de cuidados hospitalares por ser um profissional que "[...] provoca e incomoda o cotidiano hospitalar evitando sua cristalização, dada sua visão ampliada da condição humana" (Galheigo $\&$ Tessuto, 2010, p. 30). Nessa perspectiva e coerentes com os resultados da presente pesquisa, parte das intervençóes náo farmacológicas que aparecem nos textos compóem o repertório de atuação da terapia ocupacional. Porém, observou-se que raramente esse profissional é mencionado como aquele que as executa, colocando-se como premente e indispensável a necessidade de que este seja referenciado para o desenvolvimento destas açôes.

\section{Consideraçóes Finais}

A interdisciplinaridade é requerida para o gerenciamento do delirium, e o terapeuta ocupacional é profissional indispensável na composição das equipes. Suas intervençóes favorecem a melhora da autonomia, o aumento da independência no desempenho ocupacional, a promoção do bem-estar, o empoderamento do usuário e de sua rede informal no processo de cuidado. Sua atuaçáo é centrada na singularidade do sujeito e em suas necessidades, considerando a intrínseca relação entre a pessoa, o contexto, o ambiente e a realização de atividades significativas. Assim, a terapia ocupacional contribui significativamente para $\mathrm{o}$ manejo não farmacológico da complexa condiçãoo denominada delirium.

Os resultados da pesquisa indicam que a literatura referente à atuaçáo do terapeuta ocupacional no gerenciamento do delirium ainda é incipiente e limitada em relação aos dados práticos. Sugere-se, então, que estudos futuros possam se debruçar sobre suas práticas clínicas específicas, apresentando informaçôes detalhadas sobre as estratégias não farmacológicas adotadas por esses profissionais para prevenção e manejo de delirium.

\section{Referências}

Agreli, H. F., Peduzzi, M., \& Silva, M. C. (2016). Atenção centrada no paciente na prática interprofissional colaborativa. Interface: Comunicação, Saúde, Educação, 20(59), 905-916. http://dx.doi.org/10.1590/180757622015.0511 .

Alasad, J., \& Ahmad, M. (2005). Communication with critically ill patients. Journal of Advanced Nursing, 50(4), 356-362. http://dx.doi.org/10.1111/j.1365-2648.2005.03400.x.

Álvarez, E., Garrido, M. A., Tobar, E. A., Prieto, S. A., Vergara, S. O., Briceño, C. D., \& González, F. J. (2017). Occupational therapy for delirium management in elderly patients without mechanical ventilation in an intensive care unit: a pilot randomized clinical trial. Journal of Critical Care, 37, 85-90. http://dx.doi.org/10.1016/j.jcrc.2016.09.002.

Álvarez, E., Garrido, M., González, F., Guzmán, E., Donoso, T., Gallegos, S., Vergara, S., Aranda, R., Prieto, S., Briceño, C., Tobar, E., Alzamora, C., Bolvarán, C., Concha, C., Valencia, F., \& Villalobos, F. (2012). Terapia ocupacional precoz e intensiva en la prevención del delirium en adultos mayores ingresados a unidades de paciente crítico: ensayo clínico randomizado: resultados preliminares. Revista Chilena de Terapia Ocupacional, 12(1), 45-59. http://dx.doi.org/10.5354/0719-5346.2012.22051.

American Psychiatric Association - APA. (2014). Manual diagnóstico e estatístico de transtornos mentais: DSM-5. Porto Alegre: Artmed.

Balas, M. C., Vasilevskis, E. E., Olsen, K. M., Schmid, K. K., Shostrom, V., Cohen, M. Z., Peitz, G., Gannon, D. E., Sisson, J., Sullivan, J., Stothert, J. C., Lazure, J., Nuss, S. L., Jawa, R. S., Freihaut, F., 
Ely, E. W., \& Burke, W. J. (2014). Effectiveness and safety of the awakening and breathing coordination, delirium monitoring/management, and early exercise/mobility bundle. Critical Care Medicine, 42(5), 1024-1036. http://dx.doi.org/10.1097/CCM.0000000000000129.

Banh, H. L. (2012). Management of delirium in adult critically ill patients: an overview. Journal of Pharmacy \& Pharmaceutical Sciences, 15(4), 499-509. http://dx.doi.org/10.18433/J3PK69.

Campos, V. F., Silva, J. M., \& Silva, J. J. (2019). Comunicação em cuidados paliativos: equipe, paciente e família. Revista Bioética, 27(4), 711-718. http://dx.doi.org/10.1590/1983-80422019274354.

Cavallazzi, R., Saad, M., \& Marik, P. E. (2012). Delirium in the ICU: an overview. Annals of Intensive Care, 2(1), 2-11. http://dx.doi.org/10.1186/2110-5820-2-49.

Chevrolet, J. C., \& Jolliet, P. (2007). Clinical review: agitation and delirium in the critically ill-significance and management. Critical Care, 11(3), 214. http://dx.doi.org/10.1186/cc5787.

El Majzoub, I., Abunafeesa, H., Cheaito, R., Ali Cheaito, M., \& Elsayem, A. F. (2019). Management of altered mental status and delirium in cancer patients. Annals of Palliative Medicine, 8(5), 728-739. http://dx.doi.org/10.21037/apm.2019.09.14.

Finucane, A. M., Lugton, J., Kennedy, C., \& Spiller, J. A. (2017). The experiences of caregivers of patients with delirium, and their role in its management in palliative care settings: an integrative literature review. Psycho-Oncology, 26(3), 291-300. http://dx.doi.org/10.1002/pon.4140.

Galheigo, S. M., \& Tessuto, L. A. A. (2010). Trajetórias, percepções e inquietações de terapeutas ocupacionais do Estado de Sáo Paulo no âmbito das práticas da terapia ocupacional no hospital. Revista de Terapia Ocupacional da Universidade de São Paulo, 21(1), 23-32. http://dx.doi.org/10.11606/issn.2238-6149.v21i1p23-32.

Hammerschmidt, K. S. A., \& Santana, R. F. (2020). Saúde do idoso em tempos de pandemia COVID-19. Cogitare Enfermagem, 25(1), e72849. http://dx.doi.org/10.5380/ce.v25i0.72849.

Happ, M. B., Garrett, K., Thomas, D. D., Tate, J., George, E., Houze, M., Radtke, J., \& Sereika, S. (2011). Nurse-patient communication interactions in the intensive care unit. American Journal of Critical Care, 20(2), e28-e40. http://dx.doi.org/10.4037/ajcc2011433.

Herling, S. F., Greve, I. E., Vasilevskis, E. E., Egerod, I., Bekker Mortensen, C., Møller, A. M., Svenningsen, H., \& Thomsen, T. (2018). Interventions for preventing intensive care unit delirium in adults. Cochrane Database of Systematic Reviews, 11(11), http://dx.doi.org/10.1002/14651858.CD009783.pub2.

Hipp, D. M., \& Ely, E. W. (2012). Pharmacological and nonpharmacological management of delirium in critically ill patients. Neurotherapeutics: the Journal of the American Society for Experimental NeuroTherapeutics, 9(1), 158-175. http://dx.doi.org/10.1007/s13311-011-0102-9.

Hughes, C. G., Brummel, N. E., Vasilevskis, E. E., Girard, T. D., \& Pandharipande, P. P. (2012). Future directions of delirium research and management. Best Practice \& Research Clinical Anaesthesiology, 26(3), 395-405. http://dx.doi.org/10.1016/j.bpa.2012.08.004.

Ibrahim, K., McCarthy, C. P., McCarthy, K. J., Brown, C. H., Needham, D. M., Januzzi Junior, J. L., \& McEvoy, J. W. (2018). Delirium in the Cardiac Intensive Care Unit. Journal of the American Heart Association, 7(4), e008568. http://dx.doi.org/10.1161/JAHA.118.008568.

Imanishi, H. A., \& Silva, L. L. (2016). Despersonalização nos hospitais: o estádio do espelho como operador teórico. Revista da SBPH, 19(1), 41-56.

Irwin, S. A., Pirrello, R. D., Hirst, J. M., Buckholz, G. T., \& Ferris, F. D. (2013). Clarifying delirium management: practical, evidenced-based, expert recommendations for clinical practice. Journal of Palliative Medicine, 16(4), 423-435. http://dx.doi.org/10.1089/jpm.2012.0319.

Kalish, V. B., Gillham, J. E., \& Unwin, B. K. (2014). Delirium in older persons: evaluation and management. American Family Physician, 90(3), 150-158.

Kolanowski, A., Fick, D., Litaker, M., Mulhall, P., Clare, L., Hill, N., Mogle, J., Boustani, M., Gill, D., \& Yevchak-Sillner, A. (2016). Effect of cognitively stimulating activities on symptom management of delirium superimposed on dementia: a randomized controlled trial. Journal of the American Geriatrics Society, 64(12), 2424-2432. http://dx.doi.org/10.1111/jgs.14511. 
Kourkouta, L., \& Papathanasiou, I. V. (2014). Communication in nursing practice. Materia Socio-Medica, 26(1), 65-67. http://dx.doi.org/10.5455/msm.2014.26.65-67.

Meagher, D. J. (2001). Delirium: optimising management. BMJ, 322(7279), 144-149. http://dx.doi.org/10.1136/bmj.322.7279.144.

Morandi, A., Piva, S., Ely, E. W., Myatra, S. N., Salluh, J. I. F., Amare, D., Azoulay, E., Bellelli, G., Csomos, A., Fan, E., Fagoni, N., Girard, T. D., Heras La Calle, G., Inoue, S., Lim, C. M., Kaps, R., Kotfis, K., Koh, Y., Misango, D., Pandharipande, P. P., Permpikul, C., Cheng Tan, C., Wang, D. X., Sharshar, T., Shehabi, Y., Skrobik, Y., Singh, J. M., Slooter, A., Smith, M., Tsuruta, R., \& Latronico, N. (2017). Worldwide survey of the "assessing pain, both spontaneous awakening and breathing trials, choice of drugs, delirium monitoring/management, early exercise/mobility, and family empowerment” (abcdef) bundle. Critical Care Medicine, 45(11), e1111-e1122. http://dx.doi.org/10.1097/CCM.0000000000002640.

Morandi, A., Pozzi, C., Milisen, K., Hobbelen, H., Bottomley, J. M., Lanzoni, A., Tatzer, V. C., Carpena, M. G., Cherubini, A., Ranhoff, A., MacLullich, A. J., Teodorczuk, A., \& Bellelli, G. (2019). An interdisciplinary statement scientific societies for the advancement of delirium care across Europe (EDA, EANS, EUGMS, COTEC, IPTOP/WCPT). BMC Geriatrics, 19(1), 253. http://dx.doi.org/10.1186/s12877-019-1264-2.

Oh-Park, M., Chen, P., Romel-Nichols, V., Hreha, K., Boukrina, O., \& Barrett, A. M. (2018). Delirium screening and management in inpatient rehabilitation facilities. American Journal of Physical Medicine \& Rehabilitation, 97(10), 754-762. http://dx.doi.org/10.1097/PHM.0000000000000962.

Pinheiro, R. L., \& Guanaes, C. (2011). O conceito de rede social em saúde: pensando possibilidades para a prática na estratégia saúde da família. Nova Perspectiva Sistêmica, 20(40), 9-25.

Pozzi, C., Tatzer, V. C., Álvarez, E. A., Lanzoni, A., \& Graff, M. J. L. (2020). The applicability and feasibility of occupational therapy in delirium care. European Geriatric Medicine, 11(2), 209-216. http://dx.doi.org/10.1007/s41999-020-00308-z.

Quiroz, O. T., Araya, O. E., \& Fuentes, G. P. (2014). Delirium: actualización en manejo no farmacológico. Revista Chilena de Neuro-psiquiatría, 52(4), 288-297. http://dx.doi.org/10.4067/S0717-92272014000400007.

Rains, J., \& Chee, N. (2017). The role of occupational and physiotherapy in multi-modal approach to tackling delirium in the intensive care. The Journal of the Intensive Care Society, 18(4), 318-322. http://dx.doi.org/10.1177/1751143717720589.

Ramos, L. O., \& Ferreira, R. A. (2020). Sobre uma práxis interdisciplinar: aproximaçóes e proposições conceituais. Revista Brasileira de Estudos Pedagogicos, 101(257), 197-216. http://dx.doi.org/10.24109/2176-6681.rbep.101i257.4353.

Robinson, T. N., \& Eiseman, B. (2008). Postoperative delirium in theelderly: diagnosis and management. Clinical Interventions in Aging, 3(2), 351-355. http://dx.doi.org/10.2147/CIA.S2759.

Rosen, T., Connors, S., Clark, S., Halpern, A., Stern, M. E., DeWald, J., Lachs, M. S., \& Flomenbaum, N. (2015). Assessment and management of delirium in older adults in the emergency department. Advanced Emergency Nursing Journal, 37(3), 183-E3. http://dx.doi.org/10.1097/TME.0000000000000066.

Salawu, F. K., Danburam, A., \& Ogualili, P. (2009). Delirium: issues in diagnosis and management. Annals of African Medicine, 8(3), 139-146. http://dx.doi.org/10.4103/1596-3519.57235.

Souza, M. T., Silva, M. D., \& Carvalho, R. (2010). Integrative review: what is it? How to do it? Einstein, 8(1), 102-106. http://dx.doi.org/10.1590/s1679-45082010rw1134.

Stillwell, S. B., Fineout-Overholt, E., Melnyk, B. M., \& Williamson, K. M. (2010). Evidence-based practice, step by step: searching for the evidence. The American journal of nursing, 110(5), 41-47. https://doi.org/10.1097/01.NAJ.0000372071.24134.7e.

Tesser, C. D., \& Dallegrave, D. (2020). Práticas integrativas e complementares e medicalização social: indefiniçóes, riscos e potências na atenção primária à saúde. Cadernos de Saúde Pública, 36(9), e00231519. http://dx.doi.org/10.1590/0102-311x00231519.

Tobar, E., Alvarez, E., \& Garrido, M. (2017). Cognitive stimulation and occupational therapy for delirium prevention. Revista Brasileira de Terapia Intensiva, 29(2), 48-252. http://dx.doi.org/10.5935/0103-507X.20170034.

van Velthuijsen, E. L., Zwakhalen, S., Mulder, W. J., Verhey, F., \& Kempen, G. (2018). Detection and management of hyperactive and hypoactive delirium in older patients during hospitalization: a 
retrospective cohort study evaluating daily practice. International Journal of Geriatric Psychiatry, 33(11), 1521-1529. http://dx.doi.org/10.1002/gps.4690.

Whittemore, R., \& Knafl, K. (2005). The integrative review: updated methodology. Journal of Advanced Nursing, 52(5), 546-553. http://dx.doi.org/10.1111/j.1365-2648.2005.03621.x.

World Federation of Occupational Therapists - WFOT. (2010). Public statement: client-centredness in occupational therapy. London: WFOT. Recuperado em 29 de julho de 2020, de https://www.wfot.org/resources/client-centredness-in-occupational-therapy

\section{Contribuiçáo dos Autores}

Giovanna Marina Caetano e Barbara Tiemi Niyama:

Participaram de todas as etapas da concepção e

desenvolvimento do projeto de pesquisa e da redação do manuscrito. Maria Helena Morgani de Almeida: Orientou todas as etapas da concepção e desenvolvimento do projeto de pesquisa e da redaçáo do manuscrito. Marina Picazzio Perez Batista: Coorientou todas as etapas da concepçáo e desenvolvimento do projeto de pesquisa e participou de todas as etapas da redação do manuscrito. Ana Paula Pelegrini Ratier: Participou das etapas de concepçáo e delineamento do estudo, contribuindo em sua análise. Participou das etapas de concepção, sessão de resultados e revisão do manuscrito. Todos os autores aprovaram a versão final do texto.

\section{Fonte de Financiamento}

Bolsa concedida pelo Programa Unificado de Bolsas de Estudos para Apoio à Permanência e Formação de Estudantes de Graduação (PUB-USP) da Universidade de São Paulo.

\section{Autor para correspondência}

Giovanna Marina Caetano

e-mail: giovanna.caetano@fm.usp.br

\section{Editora de seçáo}

\section{Profa. Dra. Daniela Tavares Gontijo}

